УДК 528.946(571.56-25)

ВЗГЛЯД НАСЕЛЕНИЯ НА СОСТОЯНИЕ ЭКОЛОГИЧЕСКОЙ

БЕЗОПАСНОСТИ «БОЛЬШОГО ЯКУТСКА»: КАРТОГРАФИЧЕСКИЙ АСПЕКТ

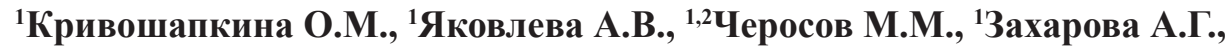
${ }^{1}$ Софронов Р.П., ${ }^{1}$ Гоголева П.А., ${ }^{1}$ Стручкова С.Г.

${ }^{1}$ ФГАОУ ВО «Северо-Восточный федеральный университет имени М.К. Аммосова», Якутск, e-mail: geometod@mail.ru;

${ }^{2}$ ФУН «Институт биологических проблем криолитозонь СО РАН», Якутск, е-mail: cherosov@mail.ru

В статье раскрываются результаты социологического исследования (анкетирование и интервью) по изучению мнения населения о состоянии экологической безопасности на территории городского округа «г. Якутск» (Большой Якутск) и непосредственно на территории г. Якутска (10 округов). В ходе полевого этапа исследования анкетированием охвачено более 500 респондентов, интервьюированием - более 130 человек. Статистическая обработка данных проводилась на основе компьютерной программы SPSS («Статистический пакет для социальных наук»). Для составления тематической карты «Личная экологическая безопасность населения на территории городских округов «Якутск» и «Жатай» выявлены компоненты: когнитивный (знаниевый), личностностно-деятельностный (поведенческий), аксиологический (ценностный) и уровни (высокий, средний, низкий) личной экологической безопасности. В результате выяснено, что когнитивный компонент сформирован у населения лучше, чем остальные два. В основу карты «Экологическая ситуация по результатам интервьюривания населения территориальных округов города Якутск» положена информация о доле респондентов, отметивших ухудшение экологической ситуации. Наиболее проблемные территории, по мнению жителей Якутска, находятся на юго-западе, в Сайсарском округе - это отметили более $90 \%$ респондентов, более благоприятная экологическая ситуация характерна для восточной и северо-восточной частей города - ухудшение экологической ситуации здесь отметили менее $30 \%$ опрошенных. Основные проблемы, беспокоящие горожан во всех городских округах: наличие мусора, загрязненная вода и загрязненный воздух, но доля респондентов, отметивших эти проблемы, колеблется по округам. Респонденты, с одной стороны, осознают недостаточный уровень защищенности от экологических опасностей, продуцируемых большим городом, с другой, сами демонстрируют скорее теоретический, чем деятельностный характер личной экологической безопасности. В связи с этим возникает необходимость принятия комплекса мер, способствующих достижению каждым жителем Большого Якутска высокого уровня личной экологической безопасности, а также обнаруживается потребность в оптимизации работы соответствующих служб по оздоровлению окружающей среды.

Ключевые слова: тематические карты, социологическое исследование, экологическая безопасность, Якутск

\title{
POPULATION VIEW ON THE STATE OF ENVIRONMENTAL SAFETY OF THE «BOLSHOI YAKUTSK»: CARTOGRAPHIC ASPECT
}

${ }^{1}$ Krivoshapkina O.M., ${ }^{1}$ Yakovleva A.V., ${ }^{1,2}$ Cherosov M.M., ${ }^{1}$ Zakharova A.G., ${ }^{1}$ Sofronov R.P., ${ }^{1}$ Gogoleva P.A., ${ }^{1}$ Struchkova S.G.

${ }^{1}$ North-Eastern Federal University, Yakutsk, e-mail: geometod@mail.ru; ${ }^{2}$ Institute of Biological Problems of Cryolithozone SB RAS, Yakutsk, e-mail: cherosov@mail.ru

The article reveals results of a sociological study (survey and interviews) on public opinion about the state of environmental safety in the territory of the City of Yakutsk (Bolshoi Yakutsk) and in the territory of Yakutsk Urban Okrug, which includes 10 districts. During field research, more than 500 respondents have been surveyed, more than 130 people have been interviewed. Statistical data processing was carried out on the basis of the SPSS («Statistical Package for Social Sciences») computer program. To compile «Population's Personal Environmental Safety in the Territory of Yakutsk and Zhatai Urban Okrugs (Districts)» topic map, the authors identified such components as cognitive (knowledge), personal-activity (behavior), axiological (value), as well as high, medium and low levels of personal environmental safety. As a result, it was found out that the cognitive component is better formed in the population than the other two. The map «The Environmental Situation According to the Results of Interviewing the Population of the Territorial Districts of the City of Yakutsk» is based on the number of the respondents who noted the deterioration of the ecological situation. According to residents of Yakutsk, the most polluted area is in the south-west, in Saysar district - more than $90 \%$ of respondents noted this, a more favorable ecological situation is typical for the eastern and north-eastern part of the city - less than $30 \%$ of respondents noted a deterioration of the ecological situation. Citizens in all urban districts are concerned about the waste, water and air pollution, but the proportion of respondents who have noted these problems varies by district. Respondents, on the one hand, aware of the insufficient level of protection against environmental hazards produced by the big city, on second, show themselves, more theoretical, than the active nature of personal environmental safety. In this regard, there is a need to take a set of measures to help every resident of Big Yakutsk achieve a higher level of personal environmental safety, and it also reveals the necessity to optimize the work of the appropriate environment health services.

Keywords: thematic maps, case study, environmental safety, Yakutsk

Согласно Конституции Российской Федерации, каждый человек имеет право на «благоприятную окружающую среду, до- стоверную информацию о ее состоянии» [1, статья 42, с. 17]. В связи с этим актуальным является социологическое исследование по 
изучению мнения населения «О состоянии экологической безопасности в Республике Саха (Якутия)», проведенное в двух городских округах Республики Саха (Якутия) «Якутск» и «Жатай». Главным понятием исследования являлась «экологическая безопасность», которая, согласно Федеральному закону «Об охране окружающей среды» понимается как «состояние защищенности природной среды и жизненно важных интересов человека от возможного негативного воздействия хозяйственной и иной деятельности, чрезвычайных ситуаций природного и техногенного характера, их последствий» [2, статья 1]. Такое состояние защищенности природы и человека во многом зависит от уровня культуры экологической безопасности, которой должно обладать общество в целом и отдельная личность в частности. Уточним, что некоторые авторы считают по сути синонимичными понятия «культура экологической безопасности» и «культура безопасности жизнедеятельности» $[3,4]$. Вопросам формирования культуры безопасности жизнедеятельности, а также выделению ее компонентов, посвящено достаточное количество исследований [5-7]. В работе Н.П. Несговоровой и др. проведен анализ публикаций, посвященных данному вопросу, и выявлены следующие компоненты культуры экологической безопасности: мотивационно-потребностный, когнитивный, деятельностно-практический, эмоционально-волевой, аксиологический, информационный и др. [4, 8]. Наше исследование посвящено характеристике «личной экологической безопасности», которую можно определить как социально-психологическую характеристику человека, отражающую его отношение к вопросам экологической безопасности и включающую три основных компонента: когнитивный (знаниевый); личностностно-деятельностный (поведенческий) и аксиологический (ценностный) (табл. 1).

С учетом вышесказанного целью исследования является выявление взгляда населения на состояние экологической безопасности «Большого Якутска» (городского округа «Якутск»), а также составление тематических карт, отражающих мнение жителей столичного региона Якутии.

\section{Материалы и методы исследования}

На основании вышеизложенного разработаны вопросы анкеты (14 вопросов) и интервью (7 вопросов) для жителей «Большого Якутска» в соответствии с выделенными компонентами структуры понятия «личная экологическая безопасность», а также определены качественные показатели ее уровней (высокий/средний/низкий). Ниже приведен фрагмент анкеты, разработанной с учетом опыта Республики Адыгея [9].

Вопросы анкеты (фрагмент):

- Как, по Вашему мнению, изменилось состояние окружающей среды в Вашем населенном пункте (городе, селе, наслеге) за последние годы?

- Каковы, по Вашему мнению, основные проблемы в области охраны окружающей среды в Вашем населенном пункте (городе, селе, наслеге)? Выберите 3 проблемы, наиболее значимые для Вас.

- Какие именно предприятия, расположенные в Вашем населенном пункте (городе, селе, наслеге), оказывают наиболее сильное негативное воздействие на состояние экологической безопасности? Впишите их названия.

- Кто, по Вашему мнению, должен заботиться об улучшении экологической обстановки в Вашем населенном пункте (городе, селе, наслеге)?

- Считаете ли Вы себя достаточно информированным о состоянии экологической безопасности в Вашем населенном пункте (городе, селе, наслеге)?

Таблица 1

Показатели сформированности личной экологической безопасности

\begin{tabular}{|c|l|}
\hline Компоненты & \multicolumn{1}{c|}{ Содержание показателя } \\
\hline $\begin{array}{c}\text { Когнитивный } \\
\text { (знаниевый) }\end{array}$ & $\begin{array}{l}\text { Знание правил и норм экологической безопасности. Степень осведомленности об эко- } \\
\text { логической безопасности своего населенного пункта }\end{array}$ \\
\hline $\begin{array}{c}\text { Личностностно- } \\
\text { деятельностный } \\
\text { (поведенческий) }\end{array}$ & $\begin{array}{l}\text { Готовность к экологически безопасному поведению. Уровень приверженности к ак- } \\
\text { тивнй деятельности в целях экологической безопасности }\end{array}$ \\
\hline $\begin{array}{c}\text { Аксиологический } \\
\text { (ценностный) }\end{array}$ & $\begin{array}{l}\text { Осознание необходимости экологически безопасного поведения. Проявление интереса } \\
\text { д экологическим проблемам своего населенного пункта. Степень понимания необхо- } \\
\text { дазвитие своей познавательной потребности по вопросам экологической безопасности }\end{array}$ \\
\hline
\end{tabular}


Особое место в анкете занимает последний вопрос «Определите уровень Вашей личной экологической безопасности», который состоит из подвопросов:

1. Я понимаю, что необходимо выполнение норм и правил экологической безопасности для сохранения собственного здоровья и здоровья будущих поколений:

а) да, согласен; б) нет, не согласен; в) затрудняюсь ответить.

2. Я умею в повседневной жизни корректировать собственное поведение с точки зрения экологической безопасности: а) всегда; б) не полностью; в) никогда; г) затрудняюсь ответить.

3. Я осуществляю практическую деятельность по осуществлению экологически безопасного проживания в своем населенном пункте (участие в субботниках; участие в озеленении и др.): а) всегда; б) не полностью; в) никогда; г) затрудняюсь ответить.

4. Я готов к самосовершенствованию с целью достижения экологической безопасности своего населенного пункта: а) да; б) не готов; в) не задумывался об этом; г) затрудняюсь ответить

Вопросы для интервью (фрагмент):

1. Считаете ли Вы, что в г. Якутске есть экологические проблемы?

2. Как изменилась экологическая ситуация в г. Якутске за последние годы?
3. Какая экологическая проблема г. Якутска вызывает у Вас особое опасение?

4. Кто должен отвечать за экологическую безопасность населения г. Якутска?

С помощью анкеты и интервью проведено социологическое исследование по изучению мнения населения «О состоянии экологической безопасности в Республике Саха (Якутия)» в двух городских округах Республики Саха (Якутия) - «Якутск» и «Жатай». В ходе полевого этапа исследования в населенных пунктах, расположенных на территории так называемого «Большого Якутска» (табл. 2), анкетированием было охвачено 527 респондентов. В интервьюировании приняли участие 137 респондентов и проводилось оно в 10 округах г. Якутска: Автодорожном, Гагаринском, Губинском, Октябрьском, Промышленном, Сайсарском, Строительном, Центральном, в микрорайонах Кангалассы и Марха.

С помощью компьютерной программы SPSS («Статистический пакет для социальных наук») был произведен ввод и статистическая обработка данных, полученных в ходе анкетирования и интервьюирования. Каждый вопрос анкеты относился к одному из компонентов личной экологической безопасности (когнитивный, личностно-деятельностный, аксиологический) и ответы респондентов распределялись по уровням: низкий, средний и высокий (табл. 2).

Таблица 2

Компоненты и уровни личной экологической безопасности населения

ГО «Якутск» и ГО «Жатай», \%

\begin{tabular}{|c|c|c|c|c|c|c|c|c|c|c|}
\hline \multirow[t]{2}{*}{$\begin{array}{c}\text { № } \\
\Pi / \Pi\end{array}$} & \multirow[t]{2}{*}{$\begin{array}{c}\text { Городской } \\
\text { округ }\end{array}$} & \multicolumn{3}{|c|}{ Когнитивный } & \multicolumn{3}{|c|}{$\begin{array}{c}\text { Личностно- } \\
\text { деятельностный }\end{array}$} & \multicolumn{3}{|c|}{ Аксиологический } \\
\hline & & $\begin{array}{l}\text { Высо- } \\
\text { кий }\end{array}$ & $\begin{array}{c}\text { Сред- } \\
\text { ний }\end{array}$ & $\begin{array}{l}\text { Низ- } \\
\text { кий }\end{array}$ & $\begin{array}{l}\text { Высо- } \\
\text { кий }\end{array}$ & $\begin{array}{c}\text { Сред- } \\
\text { ний }\end{array}$ & Низкий & $\begin{array}{l}\text { Высо- } \\
\text { кий }\end{array}$ & $\begin{array}{l}\text { Сред- } \\
\text { ний }\end{array}$ & $\begin{array}{l}\text { Низ- } \\
\text { кий }\end{array}$ \\
\hline 1 & 2 & 3 & 4 & 5 & 6 & 7 & 8 & 9 & 10 & 11 \\
\hline \multicolumn{11}{|c|}{ Городской округ «ЯКУТСК» («Большой Якутск») } \\
\hline 1 & Mapxa & 62,9 & 6,2 & 30,9 & 24 & 40,1 & 35,9 & 36,1 & 17,5 & 46,4 \\
\hline 2 & Кангалассы & 69,4 & 13,9 & 16,7 & 41,7 & 36 & 22,3 & 47,8 & 23,3 & 28,9 \\
\hline 3 & Якутск & 64,6 & 15,2 & 20,2 & 35,6 & 38,6 & 25,8 & 48,4 & 22,1 & 29,5 \\
\hline 4 & Маган & 72,3 & 7,2 & 20,5 & 41,9 & 33,8 & 24,3 & 47 & 30,2 & 22,8 \\
\hline 5 & Табага & 69,2 & 7,6 & 23,2 & 31 & 44,6 & 24,4 & 33,8 & 32,4 & 33,8 \\
\hline 6 & Хатассы & 68,2 & 13,2 & 18,6 & 40,7 & 34,8 & 24,5 & 47,9 & 26,9 & 25,2 \\
\hline 7 & Пригородный & 70,2 & 12,9 & 16,9 & 42,8 & 40,5 & 16,7 & 47,6 & 21,1 & 31,3 \\
\hline 8 & Тулагино & 54 & 16,6 & 29,4 & 41,7 & 57,3 & 1 & 42,8 & 27,8 & 29,4 \\
\hline 9 & Кильдямцы & 63 & 7,4 & 29,6 & 27,8 & 44,5 & 27,8 & 33,3 & 35,6 & 31,1 \\
\hline 10 & Сырдах & 63,5 & 10,5 & 26 & 30,2 & 37,5 & 32,3 & 41,3 & 26,4 & 32,3 \\
\hline \multicolumn{11}{|c|}{ Городской округ «ЖАТАЙ» } \\
\hline & Жатай* & 68 & 14 & 18 & 30,8 & 36,7 & 32,5 & 38,9 & 26 & 35,1 \\
\hline
\end{tabular}

П р и м е ч а н и . * До 2004 г. п. Жатай был частью города республиканского значения Якутск; в настоящее время территория Жатая полностью находится в окружении городского округа «Якутск». 


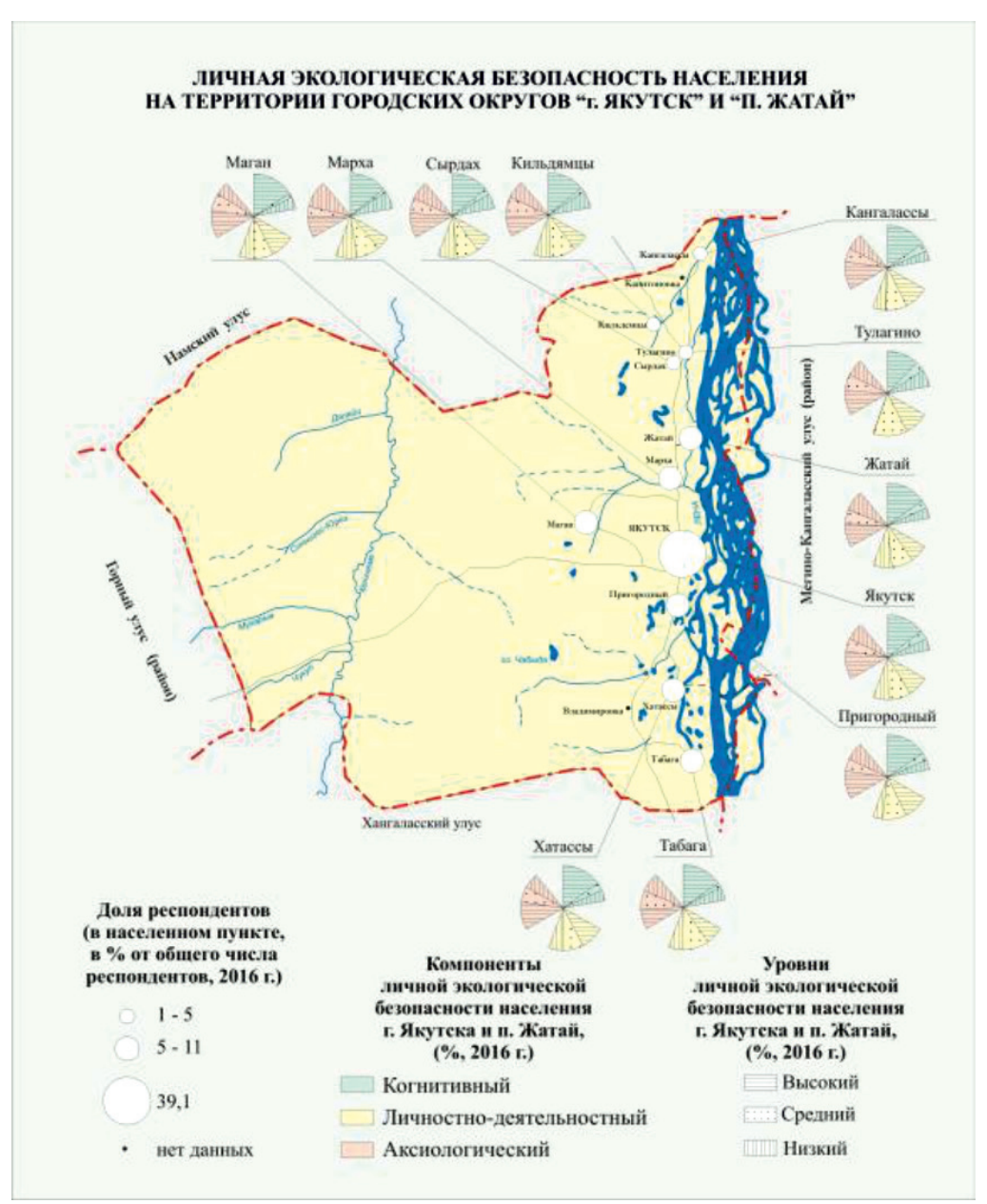

Рис. 1. Личная экологическая безопасность населения на территории городских округов «Якутск» и «Жатай»

\section{Результаты исследования и их обсуждение}

На основе полученных данных была составлена карта «Личная экологическая безопасность населения на территории городских округов «г. Якутск» и «п. Жатай»», на которую были нанесены диаграммы, показывающие по каждому населенному пункту компоненты (когнитивный, личностно-деятельностный, аксиологический) и уровни личной экологической безопасности (высокий, средний, низкий) (рис. 1).

Карта «Личная экологическая безопасность населения на территории городских округов «Якутск» и «Жатай» (рис. 1) составлена на основе анкетирования 527 жителей практически всех населенных пунктов, расположенных в пределах «Большого Якутска» (табл. 1, графа 2). Основу тематического содержания карты составляют 3 показателя: доля респондентов населенного пункта от общего числа опрошенных (пунсоны разного диаметра), а также «компоненты личной экологической безопасности» (когнитивный, личностно-деятельностный, аксиологический) и «уровни личной экологической безопасности» (высокий, средний, низкий). Обладая указанными выше компонентами, каждый житель в ходе оценки (113 вопросы анкеты) и самооценки (вопросы анкеты 14,1-14,6), показал, на каком уровне находятся эти компоненты у него лично.

Bывод 1. В результате выяснено, что знаниевый (когнитивный) компонент сформирован у населения лучше, чем остальные два, и им в высокой степени обладает большинство жителей всех населенных пунктов (max 72,3\% - Маган; min 54,0\% - Тулагино; avg $72,5 \%$ ). На втором месте по степени сформированности находится ценностный (акиологический) компонент $(\max 48,4 \%$ - Якутск; $\min 33,3 \%$ - Кильдямцы; avg - 42,3\%). И самым трудноформируемым, как и ожидалось, 
оказался личностно-деятельностный компонент личной экологической безопасности (42,8 \% - Пригородный; $\min 24,0$ \% - Марха; $\operatorname{avg}-35,3 \%)$. Для составления второй карты, отражающей уже мнение жителей непосредственно г. Якутска и его округов, использовались данные, полученные в ходе интервьюирования, проведенного студентами 4 и 5 курсов Института естественных наук. Студенты проводили опрос непосредственно на территориях вышеперечисленных округов г. Якутска. Для составления картограммы использовался показатель «Доля респондентов, считающих, что экологическая ситуация в г. Якутске ухудшилась за последние годы». Кроме того, для каждого округа составлялись картодиаграммы, показывающие три основные экологические проблемы, названные респондентами (рис. 2).
Карта «Экологическая ситуация по результатам интервьюирования населения территориальных округов г. Якутска» (рис. 2) составлена на основе опроса 137 респондентов, проживающих на территории непосредственно г. Якутска. Основу тематического содержания карты составляют 2 важных показателя: «доля респондентов, считающих, что экологическая ситуация в городе Якутске ухудшилась за последние годы» (картограмма) и «экологические проблемы, отмеченные респондентами как наиболее важные» (три проблемы) (столбчатые картодиаграммы). Кроме того, на полях карты размещено дополнительное содержание: «Изменение экологической ситуации за последние годы» и «Информированность населения об экологических проблемах» (круговые диаграммы).

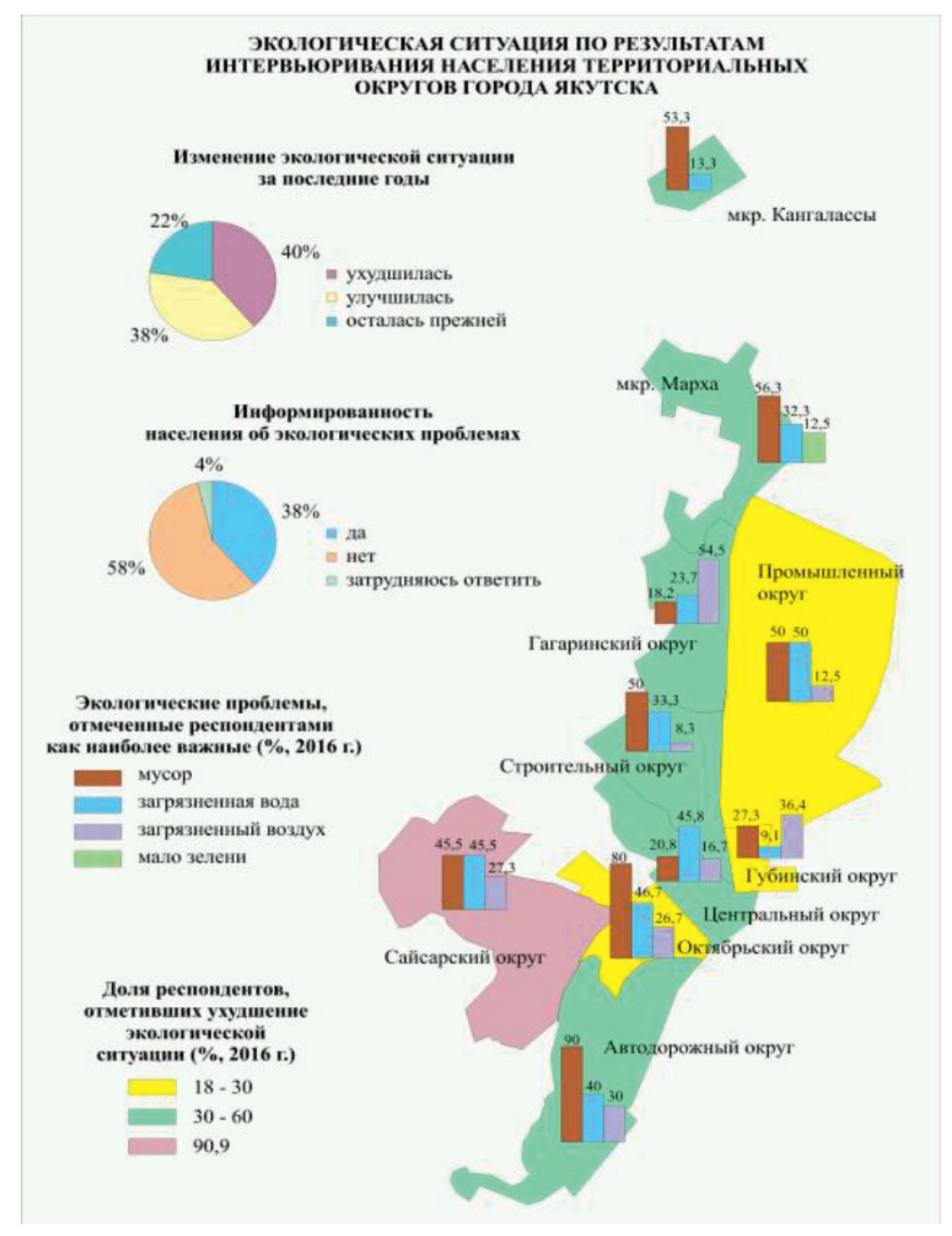

Рис. 2. Экологическая ситуаиия по результатам интервьюривания населения территориальных округов г. Якутска 
Выввод 2. Анализ карты (рис. 2) показал, что более всего озабочены ухудшением экологической ситуации респонденты, проживающие в Сайсарском округе $(90,0 \%)$, в большинстве округов доля опрошенных, считающих так же, колеблется от 30 до $60 \%$, и меньше всего отметивших ухудшение экологической ситуации проживают в Промышленном, Губинском и Октябрьском территориальных округах г. Якутска. Основные проблемы, беспокоящие горожан во всех округах: наличие мусора, загрязненная вода и загрязненный воздух, но доля респондентов, отметивших эти проблемы, колеблется по округам. В то же время совокупная доля респондентов, отметивших улучшение экологической ситуации (38\%), почти равна части считающих, что ситуация ухудшилась (40\%). Настораживает также совокупный вывод большинства респондентов (58\%), что степень их информированности в области экологических проблем низкая.

\section{Заключение}

Таким образом, анализ результатов проведенного исследования позволил сделать вывод о невысоком уровне культуры экологической безопасности жителей Большого Якутска. Респонденты, с одной стороны, осознают недостаточный уровень защищенности от экологических опасностей, продуцируемых большим городом, с другой, сами демонстрируют скорее теоретический, чем деятельностный характер личной экологической безопасности. В связи с этим возникает необходимость принятия комплекса мер, способствующих достижению каждым жителем Большого Якутска высокого уровня личной экологической безопасности, а также обнаруживается потребность в оптимизации работы соответствующих служб по оздоровлению окружающей среды. Кроме того, рекомендуется регулярно проводить социологические исследования по изучению мнения населения о состоянии экологической безопасности территории городских округов «Якутск» и «Жатай».

Исследование проводилось в рамках Программы «Комплексные научные исследования в Республике Саха (Якутия), направленные на развитие ее производительных сил и соииальной сферы в 2016-2020 г.».

\section{Список литературы / References}

1. Конституция Российской Федерации. Официальное издание. М.: Юрид. лит., 2009. 64 с. URL: http://www. constitution.ru/10003000/10003000-4.htm (дата обращения: 15.10.2018).

The Constitution of the Russian Federation. The official publication. M.: Yurid. lit., 2009. 64 p. URL: http://www. constitution.ru/10003000/10003000-4.htm (date of access: 10.15.2018) (in Russian).

2. Федеральный закон «Об охране окружающей среды» от 10.01.2002 N 7-Ф3. URL: http://www.consultant.ru/ document/cons doc LAW 34823/bb9e97fad9d14ac66df4b6e6 7c453d1be3b77b4c (дата обращения: 15.10.2018).

Federal Law «On Environmental Protection» of 10.01.2002 N 7-FZ. URL: http://www.consultant.ru/document/cons_doc LAW 34823/bb9e97fad9d14ac66df4b6e67c453d1be3b $77 \mathrm{~b} 4 \overline{\mathrm{c}}$ (date of access: 15.10.2018) (in Russian).

3. Дурнев Р.А., Пономарев А.И., Грищенко А.А. Об основах формирования культуры экологической безопасности населения Российской Федерации // Технологии гражданской безопасности. 2010. Т. 7. № 3 (25). С. 40-51.

Durnev R.A., Ponomarev A.I., Grischenko A.A. About Bases of Formation Culture Ecological Safety of the Population of the Russian Federation// Civil Security Technologies. 2010. V. 7. № 3 (25). P. 40-51 (in Russian).

4. Несговорова Н.П., Савельев В.Г., Богданова Е.П. Методика оценки компонентов культуры экологической безопасности у студентов вуза // Современные проблемы науки и образования. 2015. № 6. URL: http://www.science-education. $\mathrm{ru} / \mathrm{ru} /$ article/view?id=23553 (дата обращения: 10.10.2018).

Nesgovorova N.P., Saveliev V.G., Bogdanova E.P. Methods of assessing the components of the culture of environmental safety of university students // Modern problems of science and education. 2015. № 6. URL: http://www.science-education. $\mathrm{ru} / \mathrm{ru} / \mathrm{article} / \mathrm{view}$ ?id=23553 (date of access: 10.10.2018) (in Russian).

5. Голубева И.А. Учебно-игровая деятельность как средство формирования безопасности жизнедеятельности у студентов вуза: автореф. дис. ... канд. пед. наук. Ставрополь, 2011. 21 c.

Golubeva I.A. Educational and game activity as means of formation of health and safety of students of the university: authoref. dis. ... kand. ped. nauk. Stavropol, 2011. 21 p. (in Russian).

6. Дронов А.А. Формирование культуры безопасности жизнедеятельности студентов учреждений среднего профессионального образования: дис. ... канд. пед.наук. Воронеж, 2009. $172 \mathrm{c}$

Dronov A.A. Formation of students' health and safety culture of secondary vocational education: dis. ... kand. ped. nauk. Voronezh, 2009. 172 p. (in Russian).

7. Иванова Т.А. Педагогические условия формирования культуры безопасной жизнедеятельности детей-сирот в условиях школы-интерната: автореф. дис. ... канд. пед. наук. Владикавказ, 2008. 24 с.

Ivanova, T.A. Pedagogical conditions for the formation of a culture of life safety for orphans in a boarding school: avtoref. dis ... kand. ped. nauk. Vladikavkaz, 2008. 24 p. (in Russian).

8. Цейко В.А. Сущность и структура культуры безопасности жизнедеятельности старшеклассников // Научное обозрение. Педагогические науки. 2014. № 2. С. 150.

Tseiko V.A. The essence and structure of the culture of life safety of high school students // Scientific Review. Pedagogical sciences. 2014. № 2. Р. 150.

9. Итоги анкетирования по изучению мнения населения «О состоянии экологической безопасности в Республике Адыгея». URL: https://gshra.ru/socially/socially_51.html (дата обращения: 15.10 .2018$)$.

The results of the survey to study the opinion of the population «On ecological safety in the Republic of Adygea». URL: https://gshra.ru/socially/socially_51.html (date of access: 10.15.2018) (in Russian). 